\title{
Inhibition of the Cerebral Renin-Angiotensin System to Limit Cognitive Decline in Elderly Hypertensive Persons
}

\author{
Lionel H. Opie
}

Published online: 20 July 2011

(C) Springer Science+Business Media, LLC 2011

Keywords Renin-angiotensin $\cdot$ Brain $\cdot$ Memory $\cdot$ Cognition

\begin{abstract}
Inhibition of then renin-angiotensin system (RAS) ranks among the best established and most used cardiovascular therapies. By providing protection against hypertension and heart failure, and also the microvascular complications of diabetes, RAS inhibitors have contributed to the longer lifeexpectancy now found in higher income populations throughout the world. However, longevity propels aging persons closer to the inevitable cognitive decline. It is here that the RAS-inhibitors may also have a special role, especially in the many elderly persons with hypertension.
\end{abstract}

\section{Background}

Soon after the introduction of captopril there were anecdotal studies that those patients given this "life-style" drug "felt better". However, it was never clear whether the central benefit could be explained by blood pressure (BP) reduction or whether there was a direct effect on the brain. An early report in 1984 claimed a substantial moodelevating effect of captopril but only three patients were studied [1]. Soon thereafter Croog et al. in their famous quality of life study found that hypertensive patients taking

\footnotetext{
L. H. Opie $(\bowtie)$

Hatter Cardiovascular Research Institute, Department of

Medicine, University of Cape Town Faculty of Health Sciences

and Groote Schuur Hospital, Observatory,

Cape Town 7925, South Africa

e-mail: Lionel.opie@uct.ac.za
}

captopril had greater improvement in measures of general well-being than those taking propranolol at similar reduction of blood pressures [2]. Yet it was not clear whether captopril was better or propranolol was worse than placebo.

\section{Mechanistic Data}

Gradually mechanistic data began to accumulate concerning the role of angiotensin-II (A-II) on central function. Generation of acetylcholine was found to be an essential key to the maintenance of cognitive function, and A-II inhibited acetylcholine release in tissue taken from the human temporal cortex [3], which is regarded as the seat of memory. Furthermore, inhibition of the breakdown of acetylcholine in brain tissue improved cognitive function in a rodent model of Alzheimer's disease [4] and in elderly persons with cognitive decline [5]. Thereafter it was but a small step to postulate that drugs that inhibited the central effects of A-II would improve cognitive function and memory. Of the angiotensin-II receptor blockers (ARBs), losartan and telmisartan have been among the best studied for their effects on rodent models [6, 7]. Losartan also improved cognition when compared with equihypotensive doses of atenolol [8], while candesartan gave benefit to elderly hypertensive persons with mild cognitive impairment [9]. Thus several reports, basic and clinical, support the concept that ARBs would be likely to help in protecting human cognitive function, which includes memory.

\section{Is Brain Penetration the Answer?}

Regarding the angiotensin converting enzyme (ACE) inhibitors, logic would say that the brain penetrating agents 
are more likely to preserve memory as suggested by Ohrui et al. to explain the benefits of captopril and perindopril in a clinical study [10]. The following ACE inhibitors are classified as centrally active: captopril, fosinopril, perindopril, ramipril, trandolapril which all cross the blood-brain barrier, whereas benazepril, enalapril, moexipril and quinapril are classified as non-centrally active [11]. In a prospective substudy of the large Cardiovascular Health Study, 1054 participants, all treated for hypertension, were followed for 6 years. The major result was that centrally active ACE inhibitors were associated with $65 \%$ less decline in MiniMental State Examination (MMSE) scores per year of exposure $(P=0.01)$ Conversely, those persons taking noncentrally active ACE inhibitors showed a modest deterioration in mental status. Further experimental data supporting the benefits of brain penetrating agents comes from Yamada et al. (2010) who studied a mouse model of Alzheimer's disease, in which perindopril but neither enalapril nor imidapril improved cognitive performance [12]. Perindopril also inhibited central ACE activity by more than 50\% [12]. In another laboratory study, perindopril inhibited the increase in hippocampual ACE activity found in a mouse model of Alzheimer's disease, and improved cognition [13].

\section{Is it Merely an Effect on the Blood Pressure?}

In the largest clinical study on renin-angiotensin inhibition and cognitive function ever reported, lisinopril was the agent studied in a very detailed prospective cohort analysis on 819,491 persons on the data base of the US Veteran Affairs (VA), the extraordinarily large numbers giving great statistical weight to the findings [14]. Lisinopril was better than non-specified cardiovascular agents in delaying the onset of Alzheimer's disease and dementia, but not as good as ARBs [14]. Even better was the combination of an ARB with lisinopril. Yet the very best data were for high doses of ARBs and especially for the combination of an ARB and an angiotensin converting enzyme inhibitor. Two possible explanations are: (1) that lisinopril as a brain penetrating ACE inhibitor could influence memory beneficially and/or (2) that the blood pressure (BP) was better lowered by lisinopril than by other non-specified cardiovascular agents. Ascribing the cerebral benefits to BP lowering would also explain why cognitive function was better preserved by higher doses of the agents under study and by the combination of ARBs and lisinopril.

Of note, BP changes were not reported in the VA Study [14] even though the data should have been available. Disruption of the normal diurnal BP rhythm is closely associated with cognitive impairment via injury of the small cerebral arteries [15]. Overall, without the BP readings in the various groups understudy, this paper although otherwise compelling, does not conclusively show that the beneficial effect of ARBs or lisinopril on cognitive function is due to inhibition of central cerebral A-II receptors. However, taking the data of the Cardiovascular Health Study into account [11] the results are compatible with the concept of the central action of ARBs and centrally active ACE inhibitors.

\section{The Next Step}

As suggested by Sink et al. [11] a controlled trial using a centrally active ACE inhibitor should be prospectively tested in a large study designed to confirm the hypothesis that such an agent would preserve cognition better than a standard ACE inhibitor such as enalapril. For choice of the brain-penetrating ACE inhibitor, the agent well studied in laboratory animals is perindopril, which also helped to preserve cognitive function in the follow up of patients with a prior cerebrovascular accident [16]. On the other hand, there is also a strong case for lisinopril. Although relatively weaker on laboratory data, it was used in the largest ever clinical study [14]. The AVEC (Antihypertensives and Vascular, Endothelial, and Cognition) trial is a Bostoncentred double-blind randomized controlled clinical trial that compares 1 year of treatment of 3 antihypertensives (lisinopril, candesartan, or hydrochlorothiazide) in relation to their effect on the memory and executive function, cerebral blood flow, and central endothelial function of 100 seniors with hypertension and early objective evidence of executive or memory impairment [17]. This trial is supported by the National Institute on Aging. As hypertension is very common in the elderly, the selection of patients with hypertension is appropriate.

\section{Current Best Practice}

What should the clinician do until further large definitive prospective trials become available? My personal view would be that in managing elderly hypertensive patients who have a high probability of impending cognitive decline with the years, there is a good case for preferentially selecting brain protective RAS inhibitors. Thus the new aim would be not only to reduce BP in the elderly but also to protect cognitive function. From the available evidence, I would favour any of the ARBs with positive laboratory and especially clinical data. Among the best studied ARBs are candesartan, losartan and telmisartan (listed alphabetically, not in order of strength of supporting data). A good alternative would be to use one of the brain-penetrating ACE inhibitors (captopril, fosinopril, perindopril, ramipril, or trandolapril; again listed alphabetically). 


\section{References}

1. Zubenko GS, Nixon RA. Mood-elevating effect of captopril in depressed patients. Am J Psychiatry. 1984;141:110-1.

2. Croog SH, Levine S, Testa MA, Brown B, Bulpitt CJ, Jenkins CD, et al. The effects of antihypertensive therapy on the quality of life. N Engl J Med. 1986;314:1657-64.

3. Barnes JM, Barnes NM, Costall B, Horovitz ZP, Naylor RJ. Angiotensin II inhibits the release of $[3 \mathrm{H}]$ acetylcholine from rat entorhinal cortex in vitro. Brain Res. 1989;491(1):136-43.

4. Greig NH, Utsuki T, Ingram DK, Wang Y, Pepeu G, Scali C, et al. Selective butyrylcholinesterase inhibition elevates brain acetylcholine, augments learning and lowers Alzheimer beta-amyloid peptide in rodent. Proc Natl Acad Sci U S A. 2005;102:17213-8.

5. Petersen RC, Thomas RG, Grundman M, Bennett D, Doody R, Ferris S, et al. Vitamin E and donepezil for the treatment of mild cognitive impairment. N Engl J Med. 2005;352:2379-88.

6. Danielyan L, Klein R, Hanson LR, Buadze M, Schwab M, Gleiter $\mathrm{CH}$, et al. Protective effects of intranasal losartan in the APP/PS1 transgenic mouse model of Alzheimer disease. Rejuvenation Res. 2010;13(2-3):195-201.

7. Washida K, Ihara M, Nishio K, Fujita Y, Maki T, Yamada M, et al. Nonhypotensive dose of telmisartan attenuates cognitive impairment partially due to peroxisome proliferator-activated receptorgamma activation in mice with chronic cerebral hypoperfusion. Stroke. 2010;41(8):1798-806.

8. Fogari R, Mugellini A, Zoppi A, Derosa G, Pasotti C, Fogari E, et al. Influence of losartan and atenolol on memory function in very elderly hypertensive patients. J Hum Hypertens. 2003;17:781-5.

9. Saxby BK, Harrington F, Wesnes KA, McKeith IG, Ford GA. Candesartan and cognitive decline in older patients with hypertension: a substudy of the SCOPE trial. Neurology. 2008;70:1858-66.
10. Ohrui T, Tomita N, Sato-Nakagawa T, Matsui T, Maruyama M, Niwa K, et al. Effects of brain-penetrating ACE inhibitors on Alzheimer disease progression. Neurology. 2004;63(7):1324-5.

11. Sink KM, Leng X, Williamson J, Kritchevsky SB, Yaffe K, Kuller $\mathrm{L}$, et al. Angiotensin-converting enzyme inhibitors and cognitive decline in older adults with hypertension: results from the Cardiovascular Health Study. Arch Intern Med. 2009;169 (13):1195-202.

12. Yamada K, Uchida S, Takahashi S, Takayama M, Nagata Y, Suzuki $\mathrm{N}$, et al. Effect of a centrally active angiotensin-converting enzyme inhibitor, perindopril, on cognitive performance in a mouse model of Alzheimer's disease. Brain Res. 2010;1352:176-86.

13. Dong YF, Kataoka K, Tokutomi Y, Nako H, Nakamura T, Toyama $\mathrm{K}$, et al. Perindopril, a centrally active angiotensin-converting enzyme inhibitor, prevents cognitive impairment in mouse models of Alzheimer's disease. FASEB J. 2011 May 18. [Epub ahead of print]

14. Li N-C, Lee A, Whitmer RA, Kivipelto M, Lawler E, Kazis LE, et al. Use of angiotensin receptor blockers and risk of dementia in a predominantly male population: prospective cohort analysis. BMJ. 2010;340:b5465.

15. Nagai M, Hoshide S, Kario K. Hypertension and dementia. Am J Hypertens. 2010;23:116-24.

16. Tzourio C, Anderson C, Chapman N, Woodward M, Neal B, MacMahon S, et al. Effects of blood pressure lowering with perindopril and indapamide therapy on dementia and cognitive decline in patients with cerebrovascular disease. Arch Intern Med. 2003;163:1069-75.

17. Hajjar I, Hart M, Milberg W, Novak V, Lipsitz L. The rationale and design of the antihypertensives and vascular, endothelial, and cognitive function (AVEC) trial in elderly hypertensives with early cognitive impairment: role of the renin angiotensin system inhibition. BMC Geriatr. 2009;9:48. 